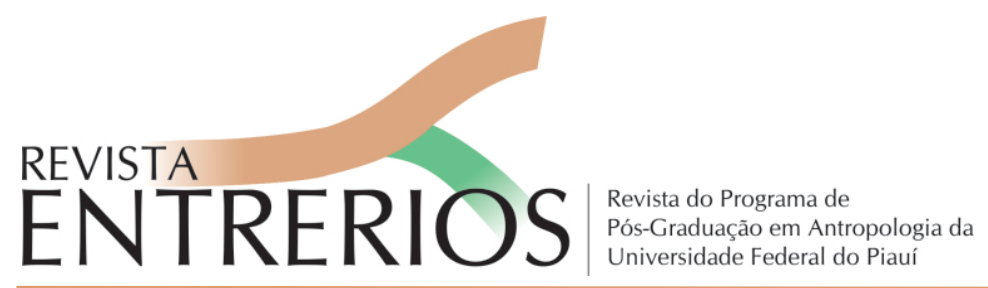

\title{
Indígenas, imigrantes e refugiados: os Warao e a proteção jurídica do Estado brasileiro
}

\section{Indígenas, inmigrantes y refugiados: los warao y la protección jurídica del Estado brasileño}

\author{
Carlos Alberto Marinho Cirino \\ Doutor em Ciências Sociais/ Antropologia - PUC de São Paulo \\ Docente da Univerdisdade Federal de Roraima -UFRR \\ carlos.cirino@ufrr.br
}

\begin{abstract}
Resumo: O artigo busca refletir sobre a situação dos Warao, da Venezuela, na condição de índios, imigrantes e refugiados no estado de Roraima, Brasil. O trabalho é construído com base em trabalhos etnográficos que trazem registros dos elementos da cultura tradicional e das mudanças ocorridas ao longo dos anos. Traçamos o percurso migratório dos Warao, ao adentrar o território brasileiro pelo município de Pacaraima, assim, como uma discussão sobre as formas de abrigamento e as políticas públicas então criadas para minorar a situação de vulnerabilidades do grupo. Num segundo momento, analisamos o modus vivendi dos Warao como abrigados para, depois, traçarmos um discurso sobre os dispositivos jurídicos que a garantem aos Warao, enquanto indios, imigrantes e refugiados direitos constitucionais $e$ infraconstitucionais. No final, uma breve reflexão sobre a pandemia en tre os Warao no abrigo.
\end{abstract}

Palavras-chave: Warao; imigrante; refugiado; direitos.

Resumen: El artículo busca reflexionar sobre la situación de los warao, de Venezuela, como indígenas, inmigrantes y refugiados en el estado de Roraima, Brasil, siendo construido a partir de trabajos etnográficos que aportan registros de elementos de la cultura tradicional y los cambios que se han producido a lo largo de los años. Trazamos la trayectoria migratoria de los warao, al ingresar a territorio brasileño por el municipio de Pacaraima, como una discusión sobre las formas de albergue y políticas públicas creadas para paliar la situación de vulnerabilidades del grupo. En un segundo momento, analizamos el modus vivendi de los warao acogidos para luego desarrollar un discurso sobre las disposiciones legales que les garantizan, como indígenas, inmigrantes y refugiados, derechos constitucionales e infraconstitucionales. Al final una breve reflexión sobre la pandemia entre los warao en el refugio estudiado.

Palabras clave: warao, inmigrante; refugiado; derechos. 


\section{Introdução}

O ensaio é resultado parcial da pesquisa em andamento sobre a imigração dos Warao desde 2016, quando da chegada dos primeiros grupos no estado de Roraima. Ao longo dos últimos três anos, temos acompanhado a saga dos Warao, a realizar pesquisas na cidade de Pacaraima, área fronteiriça com a República Bolivariana da Venezuela, na capital Boa Vista e na cidade de Manaus. Vários trabalhos etnográficos foram realizados nas três localidades. Através do Programa de Pós-Graduação em Antropologia Social da UFRR, formamos um grupo que tem buscado compreender todo o processo migratório, as políticas públicas de acolhimento, os direitos consagrados como refugiados e a dispersão no território nacional. Nossa contribuição, através dessa coletânea, é traçar um pequeno esboço da cultura tradicional dos Warao, refletir sobre as condições quando da chegada às cidades de Pacaraima, Boa Vista e Manaus. Focamos a criação dos abrigos de acolhimentos e os impactos no modus vivendi dos Warao. E finalmente, os dispositivos legais que asseguram direitos aos Warao no território nacional, a partir da própria Constituição Brasileira de1988, assim como tratados e convenções internacionais.

\section{Os Warao: alguns elementos da cultura tradicional e as mudanças ao longo do século passado.}

Ao apoiar-se em Heinen $(2011)^{1}$, passei a entender o porquê das diferentes informações etnográficas sobre a cultura dos Warao. O antropólogo observa que a heterogeneidade dos diversos subgrupos Warao se explica em decorrência das adaptações de diferentes microambientes e de distintos contatos com a população criolla ${ }^{2}$. Portanto, as mudanças não podem ser pensadas numa linearidade do grupo como um todo, haja vista que a intensidade do contato com os criollos se processou em contextos distintos. Assim, a afetação se processa de forma variada nas questões econômicas, políticas, demográficas e cosmológicas. E ele acrescenta:

No es lo mismo interactuar con los ex encomenderos de Koreabu (Curiapo), que estar al lado de un centro misional como el de San Francisco de Guayo y su numeroso grupo de criollos. Tampoco es lo mismo tratar con los funcionários de la Corporación Venezolana de Guayana la cual, para ganar tierras nuevas, construyó un dique en el caño Manamo, en el extremo occidental del Delta, o enfrentarse a los ganaderos, que reclaman, el uso de estas tierras (HEINEN, 2011: 973).

O grupo se autodenomina Warao que significa "gente da canoa" (wa: embarcação; arao: gente, habitante). Independente da procedência, os Warao são considerados "hatarao", ou seja, gente da terra alta (hota: terra alta; arao: gente, habitante) O grupo, na literatura, também é conhecido por "Guaraúnos". Os Warao estão localizados nos canais do Delta Orinoco e nas áreas próximas da Guayana Esequiba, além dos estados Bolívar, Monagas y Sucre (HEINEN, 2011: 974). Conforme assinalamos, de acordo com a situação de localização no Delta Orinoco, os Warao apresentam características diferentes frente às trocas culturais promovidas em diferentes contextos. O nicho ecológico por eles ocupado é uma faixa costeira de 70Km do Delta do Orinoco e para sobreviver, foi necessário um alto conhecimento do meio ambiente. As atividades econômicas tradicionais dos Warao se concentravam na pesca, caça e coletas de frutos silvestres, conforme as estações do ano.

1 H. Dieter Heinen nasceu na Bonn, Alemanha em 1929 e se doutorou em Antropologia pela Universidade da Califórnia em Los Angeles. Suas pesquisas estão focadas na disciplina Antropologia Econômica e Aplicada. Realizou trabalhos com população indígena Warao, Pemón e Ye'kuana. Atuou com pesquisador associado do Instituto Venezuelano de Pesquisas Científicas e como docente do Centro de Estudos Avançados/Venezuela.

2 Termo que os Warao denominam os venezuelanos não indígenas. 
Castro-Garcia (2000) também aponta os Warao como pescadores e coletores, no entanto, afirma que há mais de 70 anos tornaram-se também horticultores, cujas comunidades palafitas e as atividades de subsistência se situavam tradicionalmente nas zonas ribeirinhas (fluvial/marítimas) e úmidas.

Para Heinen (2011), poderíamos denominar de atividades de autossubsistência e, a partir dos anos 30 do século passado, adotaram a prática de cultivo de sementes em pequenas áreas para auto abastecimento. Contudo, logo iniciaram atividades produtivas para venda, como o cultivo do arroz. Com relação à divisão social do trabalho, os homens e as mulheres cooperam, conjuntamente, nas atividades produtivas, no entanto, algumas delas são rigidamente de um dos sexos, destarte a fabricação de canoas é exclusivamente do homem, assim como a construção de casas. Já as mulheres trançam os fios na fabricação de redes, responsáveis em colher a lenha e fazer o fogo para preparar a alimentação.

Para os Warao, não há uma concepção de propriedade da terra. Cada grupo ocupa uma área que esteja desocupada. Com relação ao sistema político, Heinen (2011) assinala que os Warao fazem uma distinção entre poder e autoridade que, por sua vez, seria pouco usual na nossa sociedade. $\mathrm{O}$ antropólogo ilustra essa observação e registra um fato empírico de um poderoso chefe que tinha o papel de intermediar as relações do grupo com as agências governamentais criollas, mas que foi preterido num ritual de um baile e teve que ceder o lugar a autoridade de um shamán:

Un shamán hoarotu puede tener poder porque es temido, pero no necessariamente tiene autoridad. Por otra parte, um shamán wisiratu puede tener muy poço poder, pero si gozar de gran autoridad. (...) Entre los Warao es más importante la autoridad que el poder; la meta es la armonía social, que todos queden <contentos>, <tranquilos> (oriwakaya) que haya um equilibrio y que no se imponga una decisión, kokotuka aononona takitane (HEINEN, 2011:1067).

Segundo a tradição, o chefe dos Warao é recrutado entre os anciãos, aidamo que quer dizer velho; aidamo é o chefe. Na cultura Warao, há um respeito grande pelos mais velhos, haja vista que uma das tarefas deles é manter o equilíbrio entre a sociedade, o meio ambiente e o sobrenatural.

Da forma como o poder se manifesta entre os Warao, leva-nos aduzir que o poder não tem uma essência, como preconiza Foucault (1984 X). Ele se apresenta de formas variadas e em pontos diferentes das redes sociais. Ao mesmo tempo, tanto o poder como autoridade no caso analisado, emergem como uma necessidade de manter a ordem, a harmonia, superar as tensões e os conflitos, mas não necessariamente pela imposição, percepção também corroborada por Balandier (1982: 7).

Não podemos afirmar que em todos os grupos indígenas está presente essa relação de respeito com os mais idosos, no entanto, via de regra, há uma valorização dos mais velhos frente ao papel que desempenham como depositários da memória do grupo e também com relação a fatos ocorridos no passado que marcaram a trajetória das antigas lideranças. Como exemplo, no caso das etnias de Roraima, mesmo não estar mais a frente de funções de "poder", como tuxaua (chefe), ou de funções que surgiram no contexto atual como a de professor indígena, diretor escolar, há um respeito grande pelos mais velhos, principalmente as antigas lideranças, durante as assembleias, por representarem a resistência contra as violências a que foram submetidas no passado e por terem lutado em defesa dos direitos dos povos indígenas. Geralmente, "chamadas as grandes lideranças indígenas".

Com relação às mudanças, segundo o autor, a introdução de atividades comerciais e do trabalho assalariado minou o sistema tradicional Warao, porque agora as equipes de trabalho se constituem com base em contratos comerciais em curto prazo que substituem os contratos soci- 
-ais a longo prazo, antes baseados no parentesco e alianças. As relações que se estabeleciam com os casamentos são fortemente abaladas na cultura Warao com as mudanças advindas do contato. Alguns valores culturais foram entrando em desuso, outros estão a resistir ou se redefinir. A dieta alimentar, em grande parte, foi sendo substituída por alimentos industrializados. Outro elemento impulsionador dessa mudança foi o uso da força de trabalho indígena de baixo custo nas atividades madeireiras e na plantação comercial do arroz. Os Warao também foram afetados por grandes projetos desenvolvimentistas, como as obras da "Corporación Venezolana de Guayana-CVG". A esse respeito, ressalta Hienen (2011):

Las obras realizadas por la CVG para ganar tierras aptas para la agricultura afectaron a los indígenas del Delta Bajo occidental. Por falta de presión en la corriente de la red del río Orinoco, todos los caños de la zona sufren en la época de verano la presencia de aguas salobres, con la consiguiente falta de água potable y la reducción, a um mínimo, de la muy abundante pesca fluvial. Los estudios preliminares de la CVG, a pesar de las advertencias, no enfocaron con suficiente seriedad los problemas humanos. Los que más se perjudicaron con esta situación son propios habitantes de la ciudade de Tucupita quienes están expuestos a la contaminación del caño Manamo en el que se descargan las aguas negras (HIENEN, 2011:1099).

Coincidentemente, a maior parte dos interlocutores Warao que nossa equipe de pesquisadores teve contato, tanto em Boa Vista como em Manaus, era procedente de Tucupita. Para Wilbert \& Lafée-Wilbert (2011), no marco temporal entre 1963 e 1988, os Warao teriam passado por um processo de contato mais frequente. O contato se intensifica a partir do momento em que os Warao buscam o mundo dos criollos a procura de trabalho, prestação de serviços em curto prazo, ajuda técnica, médica e/ou política. Dessa forma, houve uma abertura para os nãos índios penetraram nos territórios indígenas a levar atividades privadas extrativas ou projetos os quais necessariamente não estavam imbricados com cultura indígena Warao. Conforme Lugo (2007) os Warao passaram a ter dificuldades em termos de sustentação de suas estratégias reprodutivas, em decorrência do pouco acesso fiscal à infraestrutura e as políticas públicas governamentais. Não houve uma ação firme do Estado em várias frentes para melhorar a situação desfavorável da população indígena Warao.

Entre os projetos desenvolvimentistas que mais impactaram o território Warao, pesquisadores apontam as atividades nas indústrias madeireiras, plantações de arroz e indústrias alimentícias, construção de estradas nos anos de 1960, o programa de canalização e drenagem no Delta ocidental que afetou o habitat do grupo. Outro fato que impulsionou um deslocamento interno dos Warao foi à epidemia da cólera surgida na comunidade Mariusa entre 1992 e 1993, dizimando mais de 500 vidas. A grande maioria se deslocou em direção a Tucupita e Barrancas (HEINEN, 2011).

Com agravamento da crise econômica e política na República Cooperativista da Venezuela, a partir de 2016, diante das informações que eram levadas para pelos criollos de que no Brasil havia melhores condições de vida, principalmente alimentos, os Warao foram motivados a migrarem para o Brasil. Os criollos, por sua vez, desde 2015 já se deslocavam para o Brasil e mantinham um fluxo entre os dois países. Quando nos referimos à motivação, entendese em termo de direção, haja vista que a migração dos Warao se enquadra nas que denominamos de forçadas, conforme as experiências de contato que tiveram ao longo da sua história. $\mathrm{O}$ deslocamento forçado é qualquer tipo de migração em virtude de força maior, desde alterações climáticas, desastres naturais que coloquem em risco a vida e os direitos das pessoas. 


\section{Imigração em direção ao estado brasileiro.}

Ainda merece uma reflexão maior por parte dos pesquisadores sobre as categorias teóricas que possam entender essa caminhada dos Warao para o território brasileiro. Migração seria uma categoria mais abrangente e encontra consonância com os dispositivos legais, ao contrário de deslocamento e diáspora. Para Castiglione (2009) não há uma teoria sobre migração que possa dar conta as especificidades do fenômeno e aqui temos um caso concreto. Segundo a autora migração tem muitas dimensões. Para Rodrigues (2002) o deslocamento seria uma espécie de migração mais abrangente e de um caráter mais de permanência. A condição de refugiados dos Warao, conforme a Lei Brasileira de Refúgio, estaria relacionada, em tese, a uma possível violação de direitos humanos que estariam sendo alvo no local de origem. Mas, em termos práticos, como se deslocaram, em sua grande totalidade, numa situação de indocumentados, ao contrário dos venezuelanos não indígenas, a forma mais rápidos de dar legitimidade de permanência no país foi nessa condição.

Como já frisamos, os Warao, historicamente, já experimentavam um processo de deslocamento interno na Venezuela, consequência dos impactos socioambientais promovidos por grandes projetos que atingirem os territórios tradicionais que ocupavam. O deslocamento interno dos Warao para os centros das grandes cidades venezuelanas foi à estratégia encontrada para captar recursos financeiros e suprir necessidades não mais cobertas com os recursos naturais disponíveis nos territórios de origem, principalmente da pesca. Já inseridos no mercado de trabalho, passam a experimentar novas dificuldades com a crise econômica e política na Venezuela e inicia-se a longa caminhada para o Brasil. A grande maioria dos Warao se desloca de Tucupita, cerca de mil quilometro, até a cidade de Pacaraima, fronteira do Brasil com a Venezuela. Os Warao migram em grupos familiares extensivos, às vezes, chegam a agregar dois grupos, cuja composição gira em torno de 30 a 40 indígenas, chefiados por um ou dois aidamos. Nessa caminhada para o Brasil, a primeira parada é a cidade fronteiriça de Pacaraima/Roraima/BR, depois de transpor a última cidade venezuelana, Santa Elena de Uairén.

Em Pacaraima, os Warao ocupavam um terreno baldio a céu aberto, ao lado do Terminal Rodoviária Rubens Cabral de Macêdo e nas ruas adjacentes, em condições de muita precariedade. A permanência era passageira até conseguirem recursos financeiros com a venda de artesanatos e mendicância e seguirem à cidade de Boa Vista capital de Roraima, a cerca de 220 $\mathrm{km}$ da área fronteiriça. Na medida em que um grupo se deslocava para cidade de Boa Vista, outros chegavam continuamente. Ademais, somente em novembro de 2017 é criado o abrigo "Janokoida" em Pacaraima, palavra que, em Warao, significa "casa". No entanto, mesmo abrigados, a dinâmica de chegada e partida continuava a mesma. Em Boa Vista, os Warao se abrigaram, inicialmente, no Terminal Rodoviário Internacional José Amador de Oliveira. A visibilidade dos Warao perambulando pelas ruas de Boa Vista e mendigando nos sinais de trânsito impactava a população Boavistense, inclusive, muitas crianças em situação de vulnerabilidade. Porém, em 28 de dezembro de 2016, por determinação judicial, os Warao são levados para uma área concedida pelo Sindicato da Construção Civil de Roraima, em seguida para o Ginásio Poliesportivo do bairro Pintolândia, zona oeste da cidade de Boa Vista, abrigo que recebeu a designação de Centro de Referência ao Migrante - CRI. No início, sem muita infraestrutura, aos poucos foi se estruturando, a partir do apoio das organizações não governamentais, como o Alto Comissariado das Nações Unidas para Refugiados - ACNUR, da Ogns Fraternidade Federação Humanitária Internacional e do Exército Brasileiro que passou a atuar nas ações de acolhimento a partir de março de 2018, conforme delegação do governo federal, através do Ministério da Defesa, que passou a coordenar a logística e a segurança. 
No entanto, a dinâmica continuava a mesma, à medida que um grupo chegava ao abrigo, outros partiam para a cidade de Manaus. Na capital amazonense, instalavam-se embaixo do viaduto localizado em frente à rodoviária. A Prefeitura Municipal de Manaus, através da Secretaria da Mulher e Direitos Humanos - SEMASDH disponibilizou três imóveis residências para abrigá-los, mas insuficientes para acolher a grande quantidade de imigrantes Warao e, partir daí, se inicia uma diáspora ao longo do território nacional, conforme defende Santos (2019) em trabalho recente. Para o pesquisador, apoiado nas teses de James Clifford e Stuart Hall, o fenômeno da imigração Warao já se configura um processo diaspórico. A diáspora pressupõe longa distancias entre o local de origem e de destino, de pessoas que não têm como manter um deslocamento de mão dupla entre as duas localidades. Para Clifford (1994) esse distanciamento reflete uma condição de exilado. Da capital amazonense, grupos partem para cidades de Porto Velho/RO, Rio Branco/AC, Santarém/PA, Altamira/PA, Belém, São Luis, Teresina, Fortaleza, Natal, João Pessoa, Recife, Salvador e Belo Horizonte. Portanto, não podemos mais falar em movimento pendular dos Warao entre os dois países. A pesquisa realizada pela Organização Internacional para as Migrações - Brasil e publicada em 2018 sobre os Warao afirma que “... os indígenas retornam com frequência à República Bolivariana da Venezuela para levar dinheiro e produtos aos parentes, além de trazerem outros familiares, de modo que sua regularização no Brasil deveria ser condizente com suas práticas e necessidades" (2018: 40). O fluxo, mobilidade ou movimento pendular, em decorrência das dificuldades financeiras que não tardaram a chegar ao local de destino, como a queda nas vendas de artesanatos, haja vista a dificuldade em obter matéria prima e redução dos recursos proveniente mendicância desarticula o movimento de dupla mão de pessoas, caso dos Warao.

Assim Hannerz (1997) assinala que a palavra a fluxo não representa apenas uma noção, mas um movimento mais amplo, ligando e transcendendo questões de ordem locais e perpassando aspectos de diversas ordens: econômicos, sociais, simbólicos e culturais. Para o autor as barreiras geopolíticas não são obstáculos de circulação e fluxos de pessoas, mercadorias e informações. Mas, o que estamos chamando a atenção no nosso caso concreto ora analisado é que o fluxo de pessoas e mercadorias se tornou quase inexistente em razão da dispersão dos Warao no território nacional. Já não se trata de um deslocamento populacional de caráter não permanente, circular, pendular ou sazonal. Isso não significa a quebra do vinculo com seu local de origem e nem com as suas tradições. Quando entrevistamos alguns Warao na cidade de Manaus, eles demonstraram a incerteza em fazer um caminho de volta.

Podemos afirmar que a criação do abrigo Centro de Referência ao Migrante - CRI em Boa Vista decorreu por determinação da $1^{\text {a }}$ Vara da Infância e Juventude em dezembro de 2016, quando da tentativa de deportação de 45 (quarenta e cinco) Warao pela Policia Federal, afora a vulnerabilidade de crianças Warao em situação de moradores de ruas. No início da instalação do CRI foram abrigados imigrantes refugiados venezuelanos não indígenas e indígenas, das etnias Warao e Eñapá, os últimos em números reduzidos. O Ginásio Poliesportivo de Pintolândia não tinha uma infraestrutura física adequada para abrigá-los. Alguns ficaram amontoados na quadra de esporte. Famílias se dividiam nas arquibancadas e outros improvisaram tendas na parte externa do ginásio. Uma cozinha improvisada não oferecia condições mínimas de higienização e apenas 2 (dois) banheiros femininos e 02 (dois) masculinos para atender em torno de 400 (quatrocentos) abrigados. Mas, o maior problema era o sistema de fossas esgotadas diariamente pela Companhia de Águas e Esgotos de Roraima - CAER para que não transbordassem. A acomodação era compartilhada entre Warao e criollos, mas logo gerou conflitos e, por decisão administração, o abrigo passou a acolher apenas indígenas.

No início de 2018, a situação do abrigo já era outra, em decorrência da atuação de entidades da sociedade civil, como a Operação Anchieta, Alto Comissariado das Nações Unidas para Refugiados - ACNUR e o poder público, como a Secretaria do Bem-Estar Social do Trabalho Estado do Estado - SETRAES e a Operação Acolhida do Governo Federal. 
A Operação Acolhida passou a contar com o Exército Brasileiro, enquanto missão humanitária em território nacional. $\mathrm{O}$ abrigo passou a contar com seis grandes contêineres, logo na entrada, onde as entidades desenvolvem suas atividades administrativas. Foram instalados vários banheiros, construção de uma cozinha com fogões suspensos, não obstante alguns darem preferência cozinhar em fogueiras, conforme seus padrões culturais, 6 (seis) overliers, 36 (trinta e seis) barracas e um redário. Na ocasião do trabalho de campo, o abrigo contava com 606 (seiscentos e seis) indígenas, sendo 263 (duzentos e sessenta e três) crianças. Com as novas instalações, os Warao passaram a ter mais condições de produzir seus artesanatos e começaram escoar a produção através de uma feirinha na entrada do abrigo, geralmente aos sábados.

Porém, o que poderia se chamar de viver com mais dignidade, para os Warao, essa nova forma de "comunidade" num abrigo era/é, no mínimo, estranha e desafiadora, pois vai de encontro aos valores culturais do grupo. Isso se reflete no fato dos gestores do abrigo não conseguirem manter os abrigados sob o controle e do isolamento da sociedade envolvente. Não se tinham e não se tem um controle exato do número de Warao no abrigo, ao considerar que muitos, semanalmente, deixam o local sem prestar informações que estão indo embora, como é de costume, em grupos familiares.

As regras e normas rígidas estabelecidas no âmbito administrativo em termos de horário das atividades diárias, de fechamento dos portões, entre outros, não são compatíveis com a dinâmica cultural do grupo. Assim, não é de estranhar o encontro de Warao, ainda mendigando em sinais de trânsito na cidade de Boa Vista, mesmo considerando um número bem reduzido. $\mathrm{O}$ estado de confinamento que forem submetidos, não obstante a boa intenção dos órgãos públicos e da sociedade civil de achar que estão dando condições mais dignas de vida pode acarretar problemas de ordem psicossociais, como depressão, ansiedade e transtornos alimentares. $\mathrm{O}$ nicho ecológico tradicional ocupado pelo grupo no Delta do Orinoco é toda uma faixa costeira de $70 \mathrm{~km}$ de largura e a vida dos Warao depende de dois períodos do ciclo anual, período de chuvas e estações secas, onde o modo de viver não está desvinculado da natureza. A "casa" para os Warao não é mera habitação, mas o espaço de ocupação tradicional (HEINEN, 2011) que se configura em toda a extensão do território tradicionalmente ocupado. O confinamento no abrigo, as normas, regras, imposições, falta de autonomia é desesperador.

Essas partidas e a diáspora podem ser explicadas a partir desse status quo que se instalou na vida desses indígenas. Como os Warao partem do abrigo sem comunicação oficial, não há condições de um registro mais oficial desse movimento e semanalmente se faz uma contagem, conforme informações coletadas em lócus. Em outubro de 2018, através do acordo de cooperação entre o Tribunal de Justiça do Estado de Roraima (TJRR) e o Alto Comissariado das Nações Unidas para Refugiados (ACNUR), o Serviço de Justiça Itinerante passou a prestar serviços jurisdicionais, como emissão de documentos. Nessa data se registrava um número menor de abrigados. No ápice da emigração, tinha-se chegado a mais de setecentos e, na naquela ocasião, apenas pouco mais de 500 (quinhentos abrigados). Essa oscilação reforça a tese de um processo diáspórico: muitos partiram para Manaus e de lá seguiram para outras regiões.

Em 2019, um grupo de imigrantes refugiados venezuelanos e indígenas Warao ocupou uma grande área no bairro Jóquei Clube, zona oeste da capital de Boa Vista, um antigo clube do trabalhador, imóvel pertencente do Governo do Estado de Roraima. Ao todo 644 venezuelanos, desse total, 337 indígenas e, no geral distribuídos em 65 famílias. As crianças representavam em torno de $42 \%$ dessa população. O abrigo alternativo ${ }^{3}$ denominado de "Organización Ka' ubanoko" (na língua indígena lugar de descanso) é organizado na forma de coordenações, cada uma com as suas atribuições, a saber: religiosa e cultural, educação, segurança, comunicação, limpeza e alimentação. A população total foi dividida, administrativamente, em 06 (seis) grupos e cada um com a sua chefia.

3 As Ongs denominam esse abrigo de "Ocupação Espontânea" o que me parece estranho, haja vista que a terminologia da palavra espontânea dar o sentido de natural, sem uma motivação. Indiretamente, são forçados por não se adaptarem.

EntreRios - Revista do PPGANT -UFPI -Teresina • Vol. 3, n. 2 (2020) 
Os autoabrigados não têm interesse em ocupar os abrigos oficiais, administrados pela ACNUR e Exército Brasileiro. Alguns deles, conforme informações em lócus, já tinham passado pelos abrigos oficiais, mas não se adaptaram as normas estabelecidas. Cumpre ressaltar que o abrigo alternativo está tendo apoio da Organização Internacional para Migrações - OIM, Médico Sem-Fronteiras e Unidade de Saúde Região Cambará.

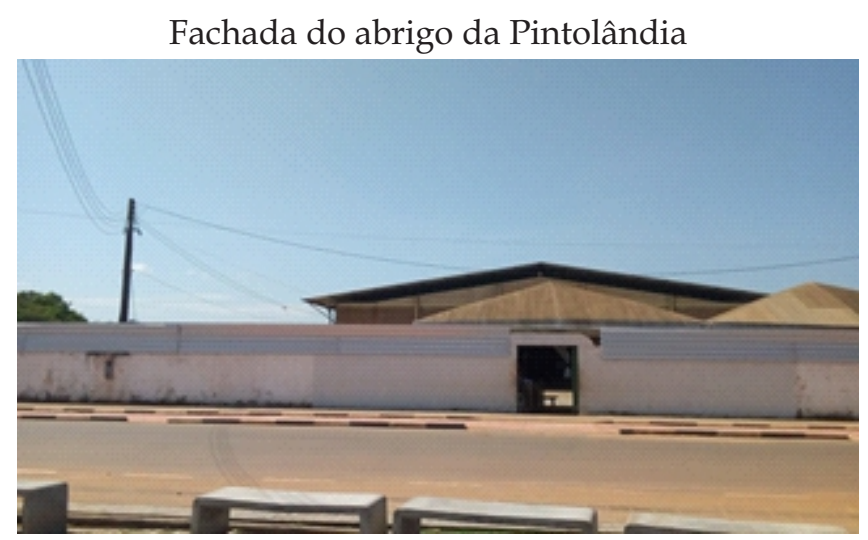

Foto: José Santos Torres, 2019.

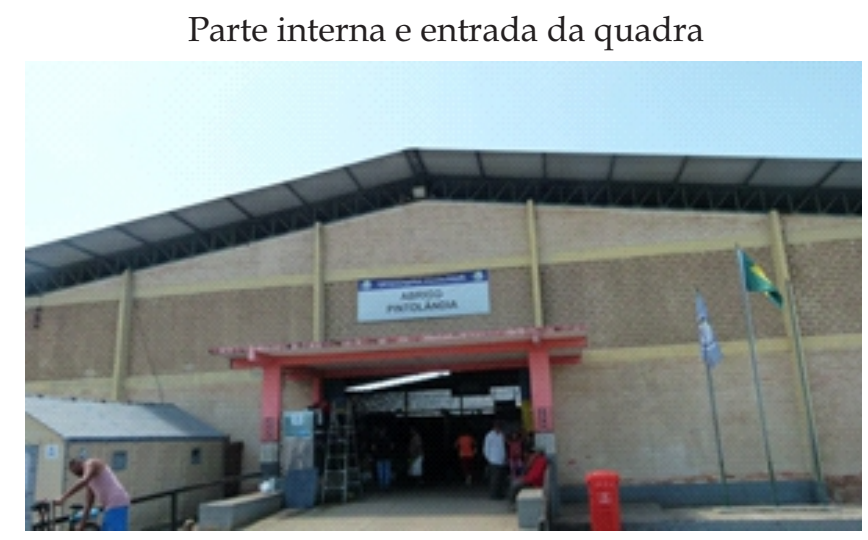

Foto: José Santos Torres, 2019.

\section{A proteção jurídica do estado brasileiro}

Quando da chegando dos primeiros grupos de Warao, o grande questionamento que se fazia com os profissionais da área de Relações Internacionais da Universidade Federal de Roraima/UFRR era quanto ao acesso aos direitos indígenas consagrados pela Constituição de 1988. Entre os questionamentos, tratava-se de uma etnia que não ocupava tradicionalmente o território no Brasil e nem a área de fronteira e, portanto, considerados estrangeiros. Durante um trabalho de campo realizado na Terra Indígena São Marcos/Pacaraima/RR, indagamos a uma das lideranças daquela TI sobre a possibilidade de concessão de uma área para os Warao. Ele informou que chegaram a discutir em pauta de uma assembleia, mas que todos foram contrários a essa possibilidade. Em outra oportunidade, quando me encontrava no Ministério Público Estadual/MPE/RR, encontrei outra liderança e perguntei como havia sido essa discussão. Ele confirmou a decisão por unanimidade e acrescentou: “eles não são índios da fronteira e são preguiçosos". Não vamos entrar nessa discussão, mas o preconceito também se manifesta entre os "iguais".

Sobre os direitos constitucionais e infraconstitucionais dos Warao no Brasil, percebemos que diante das provocações ao judiciário, entendimentos foram se consagrando, como esse que me foi enviado pelo Juiz da Vara da Justiça Itinerante do Estado de Roraima: 
A Constituição Federal, no artigo 231, reconhece aos indígenas o direito à organização social, costumes, língua, tradição e também a terra tradicionalmente ocupada. Apesar de os warao não terem terra tradicionalmente ocupada no Brasil, isto não impede o exercício dos demais direitos, já que estes não são condicionados ao lócus físico. Além disso, a Lei 5.371/67, que criou a FUNAI, e o Decreto 9.010/2017, que regulamenta seu estatuto, não restringem a sua atuação a índios brasileiros ou transfronteiriços.

A Fundação Nacional do Índio/FUNAI, por sua vez, reconhece que os migrantes têm os mesmos direitos dos demais e que os migrantes indígenas não deixam de serem índios, mas que só atuava com índios nacionais e transfronteiriços (OIM, 2018). Apesar de nada haver na legislação que assegure amparo adequado e especifico a indígena venezuelano, por sua vez, não há nada que restringem conforme citação acima.

No bojo concernente aos direitos ao Warao, cumpre citar a Resolução Conjunta $\mathrm{n}^{\circ} 03$ do Conselho Nacional do Ministério Público - CNMP e Conselho Nacional de Justiça - CNJ de 2012 que normatizou o assento de nascimento de indígenas nos cartórios de registro civil, assegurando o registro na certidão do sobrenome o nome da etnia, da aldeia de origem como informação da respectiva naturalidade, assim como nas observações consta a indicação da respectiva etnia no registrado. Ao considerar que as crianças indígenas ainda apresentam um alto índice de sub-registro, o CNJ e a Secretaria de Direitos Humanos da Presidência da República lançaram o Projeto "Cidadania, Direito de Todos" com o objetivo de erradicação do sub-registro entre os indígenas brasileiros o qual incluiu as crianças Warao nascidas no Brasil. Conforme prevê o art. 231 da Constituição Federal cuja aduz que "são reconhecidos aos índios sua organização social, costumes, línguas, crenças e tradições” cabe aos índios a livre escolha do seu nome no registro, direito extensivo às crianças Warao.

Entre os dispositivos legais aplicáveis ao caso concreto dos imigrantes Warao, destacamos a "Nova Lei de Migração", ao agregar os princípios e direitos estabelecidos na Declaração Universal dos Direitos Humanos. A nova lei preconiza, entre os diversos dispositivos, regularização documental, igualdade de tratamento e de oportunidade ao migrante e a seus familiares, inclusão social, laboral, acesso aos serviços, programas e benefícios sociais, bens públicos, educação, assistência jurídica integral pública, trabalho, moradia, serviço bancário e seguridade social. Os imigrantes Warao ainda têm amparo na Declaração dos Direitos dos Povos Indígenas, amplamente garantidos, principalmente no seu artigo 1 - "Os indígenas têm direito, a título coletivo ou individual, ao pleno desfrute de todos os direitos humanos e liberdades fundamentais reconhecidos pela Carta das Nações Unidas, a Declaração Universal dos Direitos Humanos e o direito internacional dos direitos humanos".

Outro dispositivo com força de lei é a Convenção 169 da Organização Internacional do Trabalho, que não dá condição de um tratado internacional vinculante, foi internalizado no nosso ordenamento jurídico através do Decreto $n^{\circ} 5.051 / 2004$. Entre os direitos preconizados na OIT, podemos ressaltar o artigo $2^{\circ}$ que dispõe sobre a responsabilidade que os governos deverão assumir e desenvolver, com a participação dos povos interessados, ação coordenada e sistemática com vistas a proteger os direitos desses povos e a garantir o respeito a sua integridade. Aduz ainda promover a plena realização dos direitos sociais, econômicos e culturais desses povos, respeitando sua identidade social e cultural, costumes e tradições e suas instituições, direitos já preconizados na Constituição Federal de 1988.

No que diz respeito à legislação sobre refugiados, em 1951 foi criada a Convenção da ONU que versa sobre o tema e, em 1967, o seu Protocolo. São dispositivos os quais tratam da proteção aos refugiados e que são as bases para criação de princípios, legislação, tanto internacional como local. 
A Convenção citada acima aduz que os refugiados não podem ser expulsos ou devolvidos para os territórios de origem, haja vista suas vidas ou liberdade estarem ameaçadas. Esse dispositivo estabeleceu direitos básicos que os países signatários devem prover aos refugiados. A grande contribuição do texto da Convenção foi trazer uma definição de refugiados no seu artigo $1^{\circ}$ :

I - devido a fundados temores de perseguição por motivos de raça, religião, nacionalidade, grupo social ou opiniões políticas encontre-se fora de seu país de nacionalidade e não possa ou não queira acolher-se à proteção de tal país;

II - não tendo nacionalidade e estando fora do país onde teve sua residência habitual, não possa ou não queira regressar a ele, em função das circunstancias descritas no inciso anterior;

III - devido a grave e generalizada violação de direitos humanos, é obrigado a deixar seu país de nacionalidade para buscar refúgio em outro país.

Esses dispositivos permitem aos venezuelanos imigrantes, tanto indígenas como não indígena, se regularizarem no Brasil de duas maneiras, como refugiados ou residentes temporários. Como o procedimento de refugiado é menos burocrático, geralmente os venezuelanos recorrem a esse dispositivo para, mais tarde, requererem o visto de residente temporário. No caso dos indígenas Warao, a grande maioria regulariza a situação pedindo o refúgio, devido à falta de documentação venezuelana. Com o protocolo de refúgio, podem tirar o CPF e a Carteira de Trabalho e Previdência Social.

Um acordo de cooperação celebrado entre o Tribunal de Justiça do Estado de Roraima (TJRR) e o Alto Comissariado das Nações Unidas para Refugiados - ACNUR, em 2018, possibilitou emissão de documentos e regularização e assim como a homologação de alguns acordos nas causas civis, através da Vara da Justiça Itinerante. Entre as documentações se destacam: reconhecimento de união estável, reconhecimento de paternidade, guarda de filhos menores e registro de nascimento. Chegamos a acompanhar, no segundo semestre de 2019, uma ação da Vara da Justiça Itinerante no abrigo da Pintolândia.

No início de 2019, através de uma ação civil pública, iniciaram as tratativas entre a Fundação Nacional do Índio - FUNAI, Secretaria do Estado de Educação e Desporto - SEED/RR e o Alto Comissariado das Nações Unidas para Refugiados - ACNUR no sentido promover a inclusão de crianças e jovens indígenas venezuelanas nas escolas de Boa Vista e Pacaraima, conforme recomendação da Coordenação Geral de Promoção da Cidadania -CGPC, órgão ligado a Diretoria de Promoção ao Desenvolvimento Sustentável - DPDS. Entre as recomendações, fornecer o número de profissionais da área de educação indicados para realizarem capacitação junto à FUNAI/SEED/RR, informar os procedimentos de matriculas no sentido da FUNAI analisar as discrepâncias pátria que disciplina a exigência de documentos, a situação concreta dos indígenas, um plano de matricula, possibilidade de contratação de professores indígenas venezuelanos para atuarem com tradutores da língua Warao, promoção de reuniões e oficinas de escuta com os indígenas migrantes com a finalidade de promover a inclusão, contemplar suas demandas e especificidades, preparar as escolas para receberem os alunos indígenas de forma não preconceituosa e discriminatória; informação sobre o espaço físico das escolas e supervisão de todas as recomendações pela FUNAI. Na ocasião, foram enviados a SEED/RR os dados das crianças a serem matriculadas. No abrigo Janokoida, 178 crianças entre 3 a 17 anos e 75 jovens entre 18 e 25 anos. No abrigo da Pintolândia, 227 entre 3 anos e 17 anos.

Além disso, os projetos de capacitação dos profissionais da SEER/RR chegaram a ser elaborados, mas em decorrência da pandemia no início de março, as atividades programadas 
não prosperaram. Enquanto isso, os Warao aguardam o fim da pandemia no isolamento social feito nos abrigos. Cumpre ressaltar que o fato de estarem no abrigo já é um isolamento. Eles não conseguem compreender um novo isolamento que, segundo os protocolos, os impedem de conviver em grupo. Apesar da criação de comitês no abrigo, que tentam cumprir os protocolos de prevenção do COVID-19, os Warao não conseguem assimilar a necessidade de lavarem constantemente as mãos, de manter certa distância, principalmente quando colocados em filas e acima de tudo a crença de que não vão contrair o coronavírus. Outro aspecto a considerar é que apesar do controle do abrigo, os Warao vão constantemente visitar os parentes no abrigo alternativo (ocupação espontânea).

Desde a chegada ao estado de Roraima, já se registrava um número grande de Warao acometidos de doenças respiratórias, TB, pneumonia, asma e muitas crianças desnutridas. Quanto aos contaminados com o novo coronavírus, a mídia divulgou um óbito de uma indígena Warao de 59 anos no dia 10 de maio 2020, moradora do abrigo de Pacaraima, depois de 10 dias internada no Hospital Geral de Roraima. A Secretaria Especial de Saúde Indígena - Distrito Sanitário Especial Leste de Roraima divulga boletim de casos de óbitos e de confirmados de Covid-19, mas apenas os casos notificados ao DSEI-LRR, ou seja, de indígenas aldeados. A Secretaria do Estado de Saúde, por sua vez, divulga diariamente boletim epidemiológico sobre o Covid-19, casos notificados, confirmados, descartados, recuperados e óbitos. Também descrimina por faixa etária, sexo e localidade. Portando, não temos informações sobre os casos de indígenas que moram na cidade e dos índios Warao vítimas do novo coronavírus. $\mathrm{O}$ fato de estarem abrigados numa quadra de esporte e em tendas coletivas no seu entorno, numa área murada, afora a questão cultural já aventada, nos leva a presunção de uma contaminação dos Warao em larga escala.

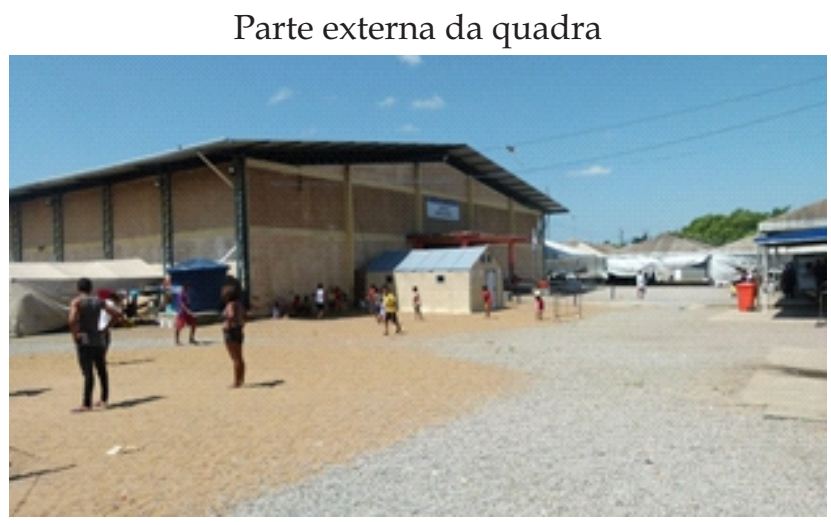

Foto: Paulo Luã Xavier, 2019.

Grupo familiar na parte externa da quadra.

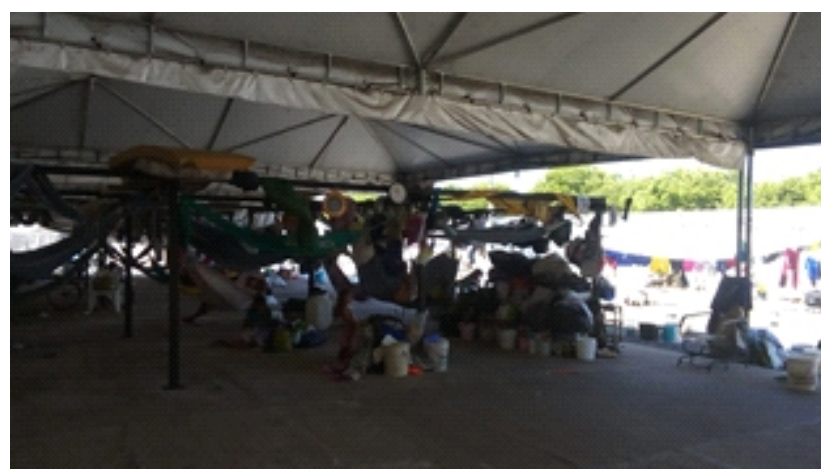

Foto: Paulo Luã Xavier , 2019. 


\section{Considerações Finais}

Conforme se constata, o fenômeno da imigração dos índios Warao para o território brasileiro é um processo dinâmico, em andamento, onde a cada momento surgem novas indagações e desafios. Por outro lado, fica evidente que se trata de uma imigração forçada, em decorrência dos impactos socioambientais ocorridos a partir da década de 60 do século passado nos territórios que, tradicionalmente, ocupavam. Segundo os autores consultados, ao longo das pesquisas bibliográficas realizadas pelo nosso grupo de estudo, é partir daí que se inicia o processo de deslocamento interno dos Warao na Venezuela.

Ademais, o outro processo é recente, decorre da crise econômica e política ocorrida nos últimos 5 anos na Venezuela. A imigração dos Warao para o território brasileiro é posterior a dos criollos. Aproximadamente, desde 2014 os venezuelanos não indígenas já entravam no Brasil pela fronteira de Pacaraima e mantinham um fluxo constante entre os dois países. Os criollos mantinham esse fluxo, ao se deslocarem constantemente à Venezuela, a levar dinheiro, produtos, principalmente gêneros alimentícios para os parentes As informações levadas s pelos criollos das oportunidades e, principalmente, de alimentos no Brasil direcionaram a imigração dos Warao para Brasil, mesmo que um percurso mais distante do que outros países fronteiriços com a Venezuela. Mas a chegada para os Warao não foi fácil, haja vista que a imigração se processa em grupos familiares extensivos, diferentemente dos criollos que chegam, geralmente, em grupos de duas ou três pessoas. Os Warao, portanto, ficavam numa situação de maior de vulnerabilidade, em acampamento, em lugares públicos, geralmente terrenos desocupados. Assim ocorreu na cidade de Paracaraima, Boa Vista e Manaus, até que o poder judicial obrigou os órgãos públicos a abrigá-los.

Por outro lado, os abrigos não ofereciam uma boa infraestrutura, principalmente o dos Warao. Mas, com o apoio das organizações não governamentais, do poder público estadual e federal, contribuíram para melhorar as condições de um modo geral. No entanto, a forma de gestão, disciplina, normas e regras impactam os sentimentos, relacionados a forma de viver do povo Warao. Na verdade, os abrigos e todas as políticas públicas voltadas para os Warao não minorou o desejo de se dispersar pelo território nacional, ao se distanciar ainda mais do local de origem. Entendemos que, nesse momento, o que parecia um simples processo de deslocamento temporário, se transformou numa grande diáspora.

E, por fim, analisamos os dispositivos nacionais e internacionais que garantem direitos aos imigrantes Warao, tanto na qualidade de índio quanto na de refugiado. Fica comprovado que os direitos dos povos indígenas no Brasil são extensivos aos Warao, apesar de não terem terras tradicionalmente ocupadas e de não habitarem áreas transfronteiriças. Destacamos algumas iniciativas já realizadas respeitando esses direitos. A mais recente, é a inclusão dos índios Warao na rede escolar do estado de Roraima.

\section{Referências bibliográficas}

BALANDIER, Georges. O Poder em cena. Brasília: Editora UNB, 1982.

CASTIGLIONI, Aurélia. Migração: abordagens teóricas. In: ARAGÓN, L. E (org.). Migração internacional na Pan-Amazônia. Belém. NAEA/UFPA, 2009.

CLIFFORD, James. Cultural Anthropology, Vol. 9, no. 3, Further Inflections: Toward

Ethnographies of the Future, 1994, pp. 302-338.

FOUCAULT, Michel. Microfísica do poder. Rio de Janeiro: Edições Graal, 4ª Ed. 1984. 295p. 
HANNERZ, Ulf. Fluxos, fronteiras, híbridos: palavras-chave da antropologia transnacional. Revista Mana, 3 (1), 1997, p7-39.

HEINEN, H. Dieter. Los Warao. In: Fundación la Salle de Ciencia Naturales. Etnologia Contemporânea: Los aborígens de Venezuela, Monografia n³5. Vol. III, Caracas: Editora Total Venezuela. 2a edição, 2011.pp. 966-1113.

LUGO, Diosey. Economia indígena y estratégias de reproducción em el grupo indígena warao. Cayapa: Revista Venezolana de Economia Social. Ano 7, $\mathrm{n}^{\circ}$ 13, Enero-Junio 2007. Universidade de Los Andes (ULA) NURR-Trujillo, 56-75.

AGENCIA DAS NAÇÕES UNIDAS PARA AS MIGRAÇÕES. Aspectos jurídicos da atenção aos indígenas migrantes da Venezuela para o Brasil. 2018.

SANTOS, José R. T. Diáspora dos índios Warao da Venezuela. Dissertação de Mestrado. PPGANTS. Universidade Federal de Roraima, 2019.

RODRIGUES, Lana Araújo. O fio do desencanto: Trajetória espacial e social de índios urbanos em Boa Vista (RR). Dissertação de Mestrado da Universidade Federal Fluminense, 2002.

WILBERT, Werner \& LAFÉE-WILBERT, Celicilia Ayla. Los Warao. Notas sobre su situación presente y actualización bibliográfica. Fundación la Salle de Ciencia Naturales. Etnologia Contemporânea: Los aborígens de Venezuela, Monografia n³5. Vol. III, Caracas: Editora Total Venezuela. $2^{\mathrm{a}}$ edição, 2011.pp. 1115-1157. 